\title{
DIVISOR: Real-time Drilling Visualizations for Virtual Reality
}

\author{
Thiago Porcino \\ FIRJAN \\ SENAI - ISI SVP \\ Rio de Janeiro, Brazil \\ tporcino@firjan.com.br
}

\section{Eric Romani \\ FIRJAN \\ SENAI - ISI SVP}

Rio de Janeiro, Brazil

eromani@firjan.com.br

\author{
Márcia Dórea \\ FIRJAN \\ SENAI - ISI SVP \\ Rio de Janeiro, Brazil \\ mclarisse@ firjan.com.br
}

\author{
Diego Barboza \\ FIRJAN \\ SENAI - ISI SVP \\ Rio de Janeiro, Brazil \\ dcbarboza@firjan.com.br
}

\author{
Wesley Oliveira \\ FIRJAN \\ SENAI - ISI SVP \\ Rio de Janeiro, Brazil \\ wloliveira@ firjan.com.br \\ João H. Batista \\ Repsol Sinopec Brazil \\ Rio de Janeiro, Brazil \\ joao.batista@repsolsinopec.com
}

fernando.perin@repsolsinopec.com

\begin{abstract}
Well drilling is one of the most expensive tasks in oilfield exploration and development projects, especially in offshore assets. Thus, this activity is under constant evolution, given that any improvement in equipment or process can result in significant savings for the company operating that field. Meanwhile, virtual reality (VR) is one of the vital industry 4.0 trends to enable simulations and training safely for users. This work aims to provide a new tool to increase the drilling team's efficiency by recreating drilling visualizations in a virtual environment. This environment enables training, evaluating, and simulating different scenarios in a well drilling and provide realtime insights to the engineers when coupled with other diagnostics tools.
\end{abstract}

Index Terms-head mounted displays, drilling, well trajectory, data visualization, real-time, virtual reality

\section{INTRODUCTION}

The drilling of an oil well consists of several phases, such as drilling, casing installation and cementing, with the reduction of the diameter of the well at each stage until reaching the objective (the reservoir), and with the monitoring of its trajectory [1]. A drilling process consists of the drill rig, drill pipes, BHA (bottom hole assembly) to drill. In the case of directional drilling, it is also required a specific composition of the drilling column, determining the well's trajectory.

To enable users to monitor the well's trajectory, it is possible to simulate countless scenarios, such as depth of the phases and types of casing [2]. Thus, these softwares' responses can assist the drilling team in choosing the best equipment, accessories, and operating conditions for an oil well. This monitoring reduces numerous problems and risks that occur during drilling activities and maneuvers [3]. However, most of this software does not have an immersive or 3-dimensional view of the data [4], [2].

Another factor is that well drilling is one of the most costly activities in this area. During the development stage of an oil production exploration project [5], especially in offshore fields, the cost for rental equipment and personnel is higher, and drilling times are longer. Meanwhile, we are experiencing the consolidation of the use of a new training platforms in virtualized environments. Virtual reality allows the visualization of realistic 3D graphics in training applications for industry, science, or military areas.

\section{A. Related Works}

In the work of [6], the construction of simulation in immersive virtual reality was carried out with the objective of training specialists in the grounding of Jackup-type oil platforms.

Leta et al. [7] present a framework for visualizing and reconstructing the geometry of drilling wells. The developed tool is capable of visualizing wells with thousands of meters. The system also has movement, zoom, rotation, and translation functionality. Unlike the work of Mostafa et al., our focus on drilling stages visualizations, which brings us closer to work presented by Leta et al. However, in this work, in addition to the visualization of well geometry, our goal is to also include data visualizations related to geometry, trajectory, and other data that concerns the decision making process for the team of drilling engineers involved.

\section{OBJECTIVE}

The project aims to read, organize, and integrate data generated by different simulation software used in the project phase with real data obtained in drilling operations for realtime visualization with VR's aid.

\section{Materials AND Methods}

We developed a $3 \mathrm{D}$ visualization system to compose the drilling observation and analysis process. The system has two usability forms: non-Immersive and Immersive (Figure $1 \mathrm{~A}$ - E). The system is connected to a unified database in the cloud with data from various sources. We get data from this database to generate visualizations, such as the historical data, 
equipment simulations data, and diagnostics data generated by artificial intelligence (AI).

The application was developed in Unity 3D using SteamVR and was designed to be used with HMDs (head-mounted displays), such as HTC Vive, HTC Vive Pro, and Oculus Rift. HMDs are proving to be an essential tool for an increase in 3D simulations' immersion. Rapid growth in the emergence of several solutions can be observed and pointed as one of the most critical simulation industry trends for the next years. While these systems provide highly immersive experiences, many users have reported discomfort symptoms, such as nausea, sickness, and headaches, among others. Cybersickness is the discomfort that occurred in HMD and also in the virtual reality environment [8]. We implement some strategies to overcome cybersickness in our application, such as teleporting and mesh optimization. We decided to construct a nonimmersive option for users that do not feel comfortable using the application virtual reality mode.

To prevent cybersickness, VR applications need to run at least 60 to 90 frames per second. Thus, it is essential to be careful with how much processing and memory the assets and scenes will take up. Scenes are rendered twice (once for each eye) in VR applications. In such a way, we applied the triangle strip method in borehole geometry, as described by Leta et al. [7].

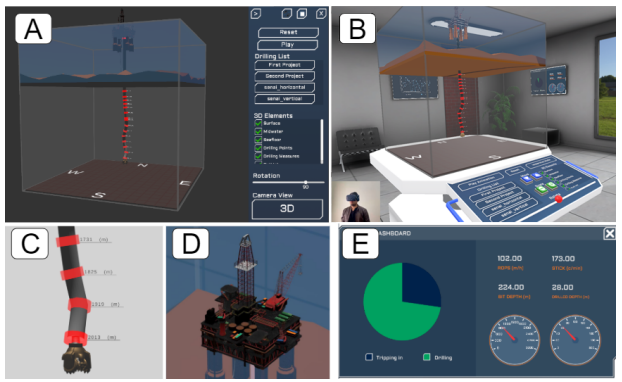

Fig. 1. Considering figures A, B, C, D, and E. (A) The non-immersive mode, (B) Immersive mode in virtual reality, (C, D) zoom and manipulation functionality in both viewing modes (immersive and non-immersive), (E) 2D graphics visualization.

\section{RESULTS}

This project is still under development. However, in its current state it is already possible to use it for some drilling analysis, such as: well path visualization, visualization of drilling stages, textual informations such as pressure, ROP and other values. Further development will include more visualizations that helps the drilling engineer in the decision making process, including 3D comparison of planned and executed projects, surface coloring to visualize pressures and other relevant data, and the predicted and simulated data provided by an artificial intelligence component and connected simulators. Moreover, we conducted interviews and tests with four drilling experts (from Repsol Sinopec). Three participants felt claustrophobia in the closed environment (office room). On the other hand, they would still like to have an environment close to the real environment. The solution was to build a "glass room" with a customizable background (Figure 2).

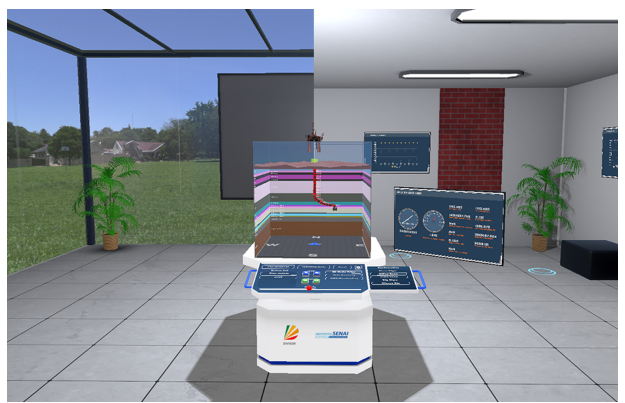

Fig. 2. The glass (left) and office (right) rooms virtual environments.

\section{CONCLUSION}

We developed a virtual reality visualization tool that enables user to analyse drilling data in an immersive and nonimmersive way. It allows the user to navigate around the virtual environment and all 3D models (such as: plataform, drill and others) and visualize data in multiple ways, perform assessments, training and simulations. Future work include extending the tool with more visualizations in a immersive and non-immersive modes, including data generated by AIs and simulators through the unified database and connecting integrating it to a company-wide Digital Twin plataform [9].

\section{THANKS}

The authors would like to thank Repsol Sinopec Brasil for this research by funding and providing real data and assets, and ESSS for collaborating with the project development.

\section{REFERENCES}

[1] H. Ho et al., "Prediction of drilling trajectory in directional wells via a new rock-bit interaction model," in SPE Annual Technical Conference and Exhibition. Society of Petroleum Engineers, 1987.

[2] C. P. Gooneratne, B. Li, and T. E. Moellendick, "Downhole applications of magnetic sensors," Sensors, vol. 17, no. 10, p. 2384, 2017.

[3] Y. T. Chan, "Drilling rig monitoring system," Oct. 7 1986, uS Patent $4,616,321$.

[4] S. Kostarev and T. Sereda, "Development of software and hardware models of monitoring, control, and data transfer to improve safety of downhole motor during drilling," in IOP Conference Series: Earth and Environmental Science, vol. 87, no. 3. IOP Publishing, 2017, p. 032016.

[5] M. J. Kaiser, "Modeling the time and cost to drill an offshore well," Energy, vol. 34, no. 9, pp. 1097-1112, 2009.

[6] A. E. Mostafa, K. Takashima, M. C. Sousa, and E. Sharlin, "Jackvr: A virtual reality training system for landing oil rigs," in International Symposium on Visual Computing. Springer, 2015, pp. 453-462.

[7] F. R. Leta, E. Clua, D. C. Barboza, J. G. F. M. Gazolla, M. Biondi, and M. S. do Souza, "Real-time visualization and geometry reconstruction of large oil and gas boreholes based on caliper database," in Visual Computing. Springer, 2014, pp. 239-254.

[8] T. M. Porcino, E. Clua, D. Trevisan, C. N. Vasconcelos, and L. Valente, "Minimizing cyber sickness in head mounted display systems: design guidelines and applications," in 2017 IEEE 5th international conference on serious games and applications for health (SeGAH). IEEE, 2017, pp. $1-6$.

[9] D. Barboza, W. de Oliveira, M. Saraiva, and L. Soares, "Demo: Virtual reality digital twin for floating production storage and offloading (fpso) units," in Anais Estendidos do XXI Simpósio de Realidade Virtual e Aumentada. Porto Alegre, RS, Brasil: SBC, 2019, pp. 31-32. [Online]. Available: https://sol.sbc.org.br/index.php/svr ${ }_{e}$ stendido/article/view/8463 